\title{
A little-known endemic caught in the South-east Asian extinction crisis: the Annamite striped rabbit Nesolagus timminsi
}

\author{
Andrew Tilker, An Nguyen, Jesse F. Abrams, Tejas Bhaghat, Minh Le \\ Thanh Van Nguren, Anh Tuan Nguren, Jürgen Niedballa \\ Rahel Sollmann and AndReas WiLting
}

\begin{abstract}
The Annamite mountains of Viet Nam and the Lao People's Democratic Republic (Lao) are an area of exceptional mammalian endemism but intensive poaching has defaunated much of the region, creating an extinction crisis for the endemic species. To make efficient use of limited conservation resources, it is imperative that conservation stakeholders obtain basic information about poorly known and threatened endemics. We present the first comprehensive information on the ecology, distribution and status of the little-known endemic Annamite striped rabbit Nesolagus timminsi. We used a systematic camera-trapping design to study the species in five areas in Viet Nam and Lao. In 29,180 camera-trap-nights we recorded 152 independent events at 36 of 266 stations. We obtained an additional 143 independent detections across 12 stations from a supplementary non-systematic survey. We analysed activity patterns and social behaviour. We also used single-species occupancy models to assess factors that influence occupancy at the landscape scale. We used $\mathrm{N}$ mixture models to obtain local abundance estimates in one target area. The Annamite striped rabbit was found to be nocturnal and primarily solitary. Species occupancy was best explained by a proxy for past hunting pressure, with no significant relationships to current anthropogenic or environmental factors. Local abundance was 0.57 individuals per camera-trap station for one of our sites, and estimated to be zero at the other site where hunting appears to have been more intense. Our results provide information on
\end{abstract}

Andrew Tilker* (Corresponding author), An NGuYen* ${ }^{*}$ Jesse F. Abrams, Tejas Bhagwat†, Thanh Van Nguyen $\$$, Jürgen Niedballa and Andreas Wilting Leibniz Institute for Zoo and Wildlife Research, Alfred-Kowalke-Straße 17, 10315, Berlin, Germany. Email tilker@izw-berlin.de

Minh Le‡ and Anh Tuan NguYen Hanoi University of Science, Department of Environmental Ecology, Hanoi, Viet Nam

Rahel Sollmann Department of Wildlife, Fish, and Conservation Biology, University of California Davis, Davis, California, USA

${ }^{*}$ Also at: Global Wildlife Conservation, Austin, Texas, USA

$\dagger$ Also at: Department of Geosciences, University of Bayreuth, Bayreuth, Germany

$\ddagger$ Also at: Central Institute for Natural Resources and Environmental Studies, Viet Nam National University, Hanoi, Viet Nam

Received o6 December 2017. Revision requested 2 February 2018. Accepted 12 April 2018. First published online 19 November 2018. priority areas for targeted anti-poaching efforts and give the first conservation baseline for the species.

Keywords Annamite mountains, Annamite striped rabbit, Nesolagus timminsi, N-mixture, occupancy, snaring, South-east Asia, tropical rainforest

Supplementary material for this article is available at https://doi.org/10.1017/So030605318000534

\section{Introduction}

Couth-east Asia is a global biodiversity hotspot with $\checkmark$ exceptionally high levels of mammalian richness and endemism (Schipper et al., 2008). Rapid rates of deforestation and widespread poaching have caused precipitous declines in mammals across the region (Duckworth et al., 2012), driving regional extinctions of several conservationpriority species (Brook et al., 2012) and threatening others with global extinction (Tilker et al., 2017). However, even in this biodiversity hotspot, diversity and threat levels are not uniformly distributed. Subregional centres of endemism are of particular concern from a conservation perspective because small global geographical range is a strong predictor of extinction risk (Cardillo et al., 2008). To design effective mitigation mechanisms for range-restricted species in endemism hotspots it is imperative that conservation scientists obtain basic information on status and distribution, as well as an understanding of the effect of anthropogenic pressures. This information is especially critical for little-known endemic species that occur in areas that are known to be under threat.

The Annamite Range, a mountain chain straddling the border of Viet Nam and Lao People's Democratic Republic (Lao), has one of the highest concentrations of endemic mammal species in continental South-east Asia (Baltzer, 2001; Tordoff et al., 2003). Several of these species are new to science, highlighting how little is known about the biodiversity of this ecoregion (Sterling \& Hurley, 2005). All Annamite endemic mammals are facing an extinction crisis. Although habitat loss has been a factor in their decline, the primary threat is intensive poaching through the use of wire snares (Gray et al., 2017, 2018) to 
supply the thriving wildlife trade in Indochina (Sodhi et al., 2004; Harrison et al., 2016). Although snaring is prohibited by law in both Viet Nam and Lao, enforcement is weak and most protected areas are so-called paper parks that offer little or no protection to conservation-priority species (Brook et al., 2012). As a result of high demand for wildlife products and lax enforcement, industrial-level commercial snaring is pervasive and has caused widespread empty forest syndrome (Redford, 1992) across the entire Indochina region.

The Annamite striped rabbit Nesolagus timminsi is amongst the most understudied of the endemic mammals of this region and is currently categorized as Data Deficient on the IUCN Red List (Abramov et al., 2008). The species was first discovered by scientists in 1996 from specimens found in a local market in central Lao (Surridge et al., 1999; Averianov et al., 2000) and shortly thereafter was confirmed to occur in neighbouring Viet Nam (Dang et al., 2001). With a dark dorsal stripe, rustcoloured rump, and short tail and ears, it is unlike any other lagomorph in mainland South-east Asia. The little information that biologists have indicates that the species is restricted to wet evergreen forest with little or no dry season and has no clear elevational preference (Abramov et al., 2008). The species' known range extends from the northern to central Annamites (Dang et al., 2001; Abramov et al., 2008). Like all terrestrial mammals in the Annamites it is threatened by snaring (Dang et al., 2001; Abramov et al., 2008; Tilker et al., 2017).

Standardized surveys are needed to obtain the basic information necessary to make informed conservation management decisions for the Annamite striped rabbit. However, obtaining robust data on the species has proven challenging, both because of the dense tropical rainforest and rugged terrain where it lives and the fact that densities of all mammals are severely depressed across the Annamites. Automatic camera traps provide an effective way to gather data on the species. We conducted systematic camera trapping across five areas in Viet Nam and Lao with the objective of gathering information on the ecology, distribution and status of the Annamite striped rabbit. Here we present data on the species' activity patterns and sociality, analyse its distribution and the factors influencing its occurrence using an occupancy model framework, and use an $\mathrm{N}$-mixture framework to estimate local abundance. We discuss the implications of our results for the conservation of this little-known endemic species.

\section{Study area}

We conducted camera-trap surveys in a large forest block in the central Annamites landscape spanning both Viet Nam and Lao. The forest is divided into five administrative areas. In Viet Nam, surveys were conducted in three protected areas: Bach Ma National Park and the Thua Thien
Hue and Quang Nam Saola Nature Reserves. In Lao, surveys were conducted in the eastern section of Xe Sap National Protected Area and an adjacent ungazetted forest block to the south near the village of Ban Palé (Fig. 1). Together these areas cover c. $900 \mathrm{~km}^{2}$. The study area has a tropical monsoon climate and is characterized by rugged terrain, with elevations of $100-2,000 \mathrm{~m}$. The dominant habitat type is closed-canopy wet evergreen forest. Montane forest occurs at the highest elevations (above c. 1,300 m). Forests in this area have an extensive history of past disturbance, including chemical defoliation during the Viet Nam war (Stellman et al., 2003), state-enterprise logging during the 1970 and 1980s (Yen et al., 2005), and ongoing illegal timber extraction. Bach Ma National Park and the Saola Nature Reserves are surrounded by a densely populated humanmodified landscape. By contrast, population density in the Lao sites is low and they do not contain extensive humanmodified areas. However, the Lao sites are heavily utilized by Vietnamese poachers, and subject to mining and illegal logging operations (Tilker, 2014). A road bisecting the eastern section of Xe Sap National Protected Area and the Palé area facilitates access from neighbouring Viet Nam. Despite this accessibility, the Pale area (c. $\left.150 \mathrm{~km}^{2}\right)$ is one of the least surveyed areas in the Annamites. The lack of past survey effort could be because of its particularly difficult terrain: elevations are $500-2,000 \mathrm{~m}$ (mean $=1,109 \pm$ SD 307 ), with $59 \%$ of the area above $1,000 \mathrm{~m}$, and a mean slope of $25.89 \pm \mathrm{SD} 10.47^{\circ}$.

Levels of active protection are generally low but vary in intensity across the landscape. Since 2011, WWF has provided support to the local government counterparts in protected area management in both Viet Nam and Lao. As part of this initiative, snare-removal teams have been active in the Saola Nature Reserves and eastern Xe Sap National Protected Area. In a 5-year timespan the teams removed $>75,000$ snares from the Saola Nature Reserves (Gray et al., 2018). There is no evidence of active patrolling efforts in Bach Ma National Park and Palé. Historically, these sites supported a representative suite of Annamite endemic and near-endemic species, including the saola Pseudoryx nghetinhensis, Owston's civet Chrotogale owstoni, the large-antlered muntjac Muntiacus vuquangensis and Edwards's pheasant Lophura edwardsi (Tordoff et al., 2003; Sterling \& Hurley, 2005). However, intensive snaring has wiped out many terrestrial mammal and bird species (Harrison et al., 2016; Tilker et al., 2017; Gray et al., 2017, 2018).

\section{Methods}

\section{Data collection and preparation}

Systematic camera trapping was conducted during November 2014-December 2016 in two phases: (1) a coarsegrid phase, in which camera-trap stations were spaced c. $2.5 \mathrm{~km}$ apart across the study site, and (2) a fine-grid 


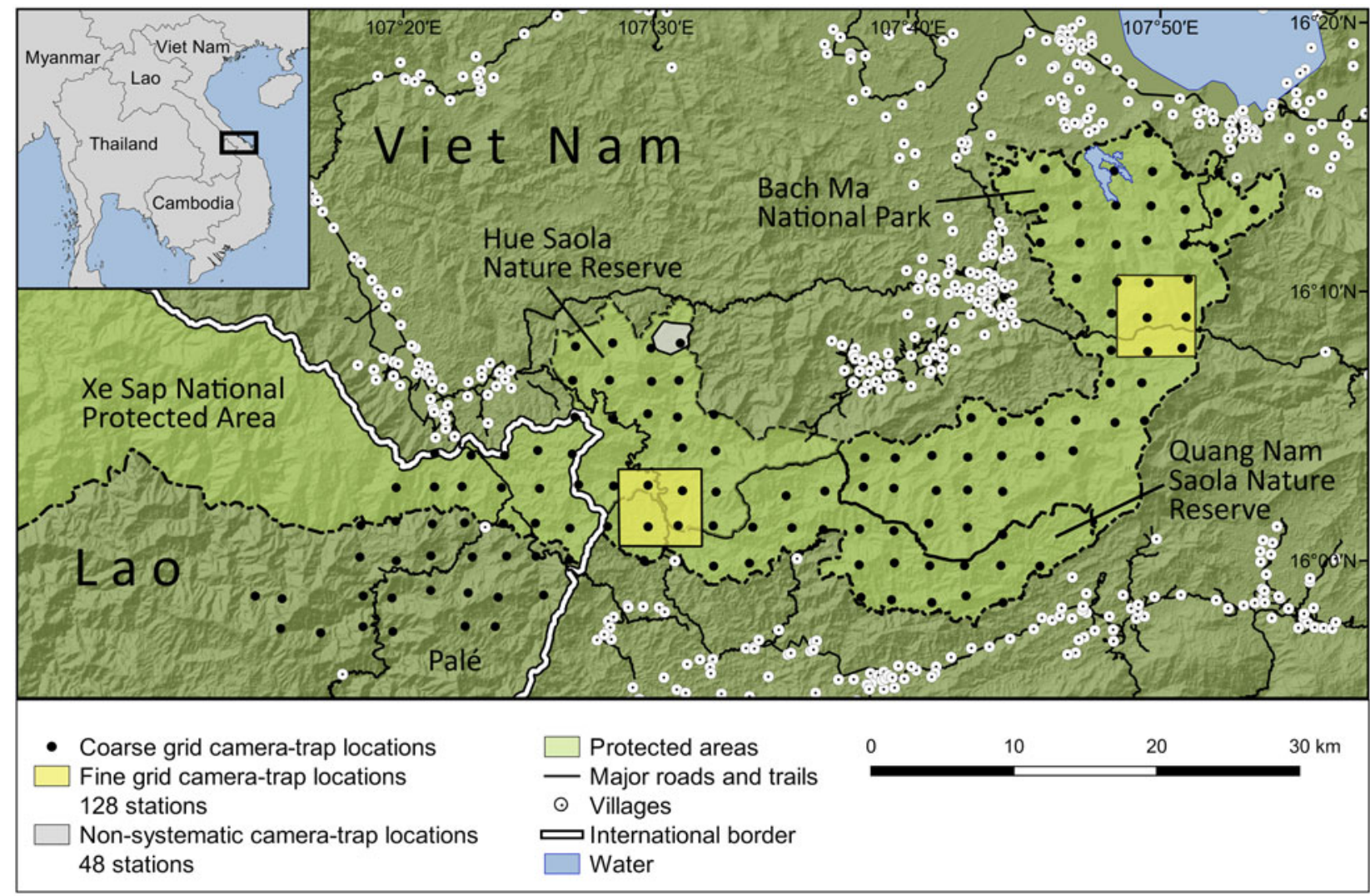

FIG. 1. Camera-trap locations across all study sites in the central Annamites landscape of Viet Nam and Lao.

phase, during which intensive camera trapping was conducted over a smaller area using a clustered design (Fig. 1). Camera traps were stationed along animal trails, ridgelines and water sources to maximize mammal detections. All cameras were placed on trees, $20-40 \mathrm{~cm}$ above the ground, were operational 24 hours per day, and were left in the field for a minimum of 60 days. At each station two independent white-flash camera traps (Reconyx Hyperfire Professional PC850; Reconyx, Holmen, USA) were set. The coarse-grid phase was designed to provide data that could be analysed in an occupancy framework. A total of 138 coarse-grid stations were set up across the five sites: 53 stations in Bach Ma National Park, 46 in the Saola Nature Reserves, and 39 in the Xe Sap National Protected Area and Pale area. In this phase, the two cameras at each location were set facing in different directions. For analysis, we treat the two cameras as a single station. We conducted the coarse-grid camera trapping over three consecutive time periods (Table 1).

The fine-grid survey was conducted in core areas of Bach Ma National Park and the Saola Nature Reserves, where a total of 128 individual stations were set up (64 at each location). The stations were arranged in 16 clusters, spaced c. $1.5 \mathrm{~km}$ apart. Each cluster consisted of four camera-trap stations, spaced c. $500 \mathrm{~m}$ apart and arranged in a square. At each station a pair of cameras was positioned facing each other to photograph both sides of a passing animal. The fine-grid phase was designed to provide data that could be used to estimate density or abundance for species that have individually recognizable markings. Exact finegrid survey locations within the larger protected areas were chosen to cover areas that appeared to support higher-than-average mammal densities based on information from the coarse-grid dataset.

In addition to the systematic survey, we use data from an opportunistic camera-trap survey (Bushnell Trophy Cam; Overland Park, USA) conducted in the Hue Saola Nature Reserve during November 2015-January 2017, to provide additional information on activity patterns and sociality of the Annamite striped rabbit.

To examine factors that influence Annamite striped rabbit occupancy across our study site we assessed habitat-related and anthropogenic features at both microand macro-scales (Table 2). In the field we established a $20 \times 20 \mathrm{~m}$ grid around the centre point of our coarse-grid stations to demarcate the area for which we collected microhabitat data. We took canopy photographs at the centre point and the corners of the grid to characterize the microhabitat vegetation. To assess vegetation density, we took photographs in each cardinal direction of a $1 \times 1.5 \mathrm{~m}$ orange sheet positioned $10 \mathrm{~m}$ from the centre point. Other in situ habitat features that we measured include the number of 
TABLE 1. Details of camera-trap surveys conducted in a large forest block in the central Annamites landscape of Viet Nam and Lao (Fig. 1), with survey site, phase, date, number of stations, number of trapping days, number of detections of the Annamite striped rabbit Nesolagus timminsi, and number of detections of mammal and large galliform species.

\begin{tabular}{|c|c|c|c|c|c|c|}
\hline Site & Survey phase & Survey dates & $\begin{array}{l}\text { No. of } \\
\text { stations }\end{array}$ & $\begin{array}{l}\text { Total no. of } \\
\text { camera-trap days }\end{array}$ & $\begin{array}{l}\text { Detections of } \\
\text { Annamite } \\
\text { striped rabbit* }\end{array}$ & $\begin{array}{l}\text { Detections of } \\
\text { mammals \& large } \\
\text { galliforms }\end{array}$ \\
\hline \multirow[t]{2}{*}{ Bach Ma National Park } & Coarse grid & $\begin{array}{l}\text { Nov. 2014-Jan. } 2015 \\
\text { July-Oct. } 2015\end{array}$ & 53 & 6,742 & 8 & 612 \\
\hline & Fine grid & Mar.-May 2015 & 64 & 4,146 & 0 & 906 \\
\hline Hue \& Quang Nam & Coarse grid & Aug.-Dec. 2015 & 46 & 6,480 & 48 & 978 \\
\hline \multirow[t]{2}{*}{ Saola Nature Reserves } & Fine grid & Dec. 2015-Mar. 2016 & 64 & 4,347 & 54 & 1,082 \\
\hline & Non-systematic & Nov. 2015-Jan. 2017 & 48 & 17,190 & 142 & \\
\hline $\begin{array}{l}\text { Xe Sap National } \\
\text { Protected Area/Palé } \\
\text { region }\end{array}$ & Coarse grid & July-Dec. 2016 & 39 & 7,465 & 44 & 552 \\
\hline
\end{tabular}

${ }^{\star} \Delta=60$ minutes.

bamboo stands, number of dead fallen trees, and number of water sources within the grid. To assess human activity at the camera-trap locations, we recorded human signs. Landscape-level features were evaluated using remote imagery and available geographical information system (GIS) layers. We used $5 \mathrm{~m}$ resolution $3 \mathrm{~A}$ level RapidEye imagery for remote sensing. We used the Random Forest model from the randomForest package in $R$ 3.4.o (R Development Core Team, 2016) to group imagery into five categories: forest, plantations, degraded areas, bare ground, and water. To evaluate habitat quality we used a weighted mean to calculate forest score, with weights given as follows: plantations, roads and bare areas $=0$, degraded areas $=1$, and forest $=2$. In this classification scheme a higher score corresponds to higher habitat quality. Forest score was calculated within a $50 \mathrm{~m}$ radius of each station (following Niedballa et al., 2015).

Terrain ruggedness was measured within a $270 \mathrm{~m}$ neighbourhood around each station using a shuttle radar topography mission (SRTM) $30 \mathrm{~m}$ digital elevation model. We also used the digital elevation model to further enhance water class by creating a hydrology layer using the r.terraflow function in QGIS 2.18.9 (QGIS Development Team, 2016), then calculated Euclidean distance from major streams with package gDistance in $R$. Euclidean distance to villages and roads was also calculated with gDistance.

Two other anthropogenic factors that could influence Annamite striped rabbit occupancy are current protection levels and past hunting pressure. To evaluate current protection we assigned each study area a binary score: 1 indicates presence of active snare-removal teams and o indicates no known patrolling. To approximate past hunting levels we used the number of detections of snaring-sensitive species, defined as all mammals and galliforms with body mass $>500 \mathrm{~g}$, scaled by the number of days the camera trap was active. However, we recognize the possibility that other ecological or sampling-based factors, such as camera- trap placement, may influence detection rates (Sollmann et al., 2013). To mitigate this, we derived the detection rate for species not likely to be caught in snares, defined as all mammals and galliforms with body mass $<500 \mathrm{~g}$, and included this as a covariate in our occupancy analyses. If detection rates are driven by camera-trap placement or movement behaviour we would expect a correlation between detections of large and small vertebrates, and between these detection rates and the detection rate of Annamite striped rabbits. However, using a Pearson correlation test we found no strong correlations between any of our detection rates $(r<0.4$; Supplementary Fig. 1). Therefore, we conclude that neither camera-trap placement nor similar movement patterns of Annamite striped rabbits and other mammals strongly influenced detectability. As a result we expect that, if detection rates for large vertebrates are reflective of past hunting pressure, only this detection rate would influence Annamite striped rabbit occupancy.

All continuous covariates in the occupancy analyses were standardized to have mean $=0$ and $S D=1$. We tested for collinearity between all possible pairs of continuous covariates, using Pearson's correlation plots; no covariates were highly correlated ( $r<0.7$; Supplementary Fig. 2).

\section{Data analysis}

All analyses were conducted in $R$. We used the camtrapR package (Niedballa et al., 2016) to prepare cameratrapping data. To assess Annamite striped rabbit activity patterns we compiled all independent detections $(\Delta=60$ minutes) and then used the $R$ package overlap to plot a kernel density estimation of daily activity. Sociality was assessed by recording the number of individuals in photographic sequences.

We fitted occupancy models to Annamite striped rabbit detections from the coarse grid. We consider our 6o-day 
TABLE 2. Covariates used for Annamite striped rabbit occupancy modelling.

\begin{tabular}{|c|c|c|c|}
\hline Covariate & Scale $^{1}$ & Type $^{2}$ & Description \\
\hline Bamboo & Micro & Environmental & Number of bamboo stands within $20 \times 20 \mathrm{~m}$ plot around the camera-trap station \\
\hline Canopy closure & Micro & Environmental & $\begin{array}{l}\text { Proportion of visible sky averaged across five locations around the camera-trap } \\
\text { station }\end{array}$ \\
\hline Dead fallen trees & Micro & Environmental & Number of dead fallen trees within $20 \times 20 \mathrm{~m}$ plot around the camera-trap station \\
\hline Distance to roads & Macro & Anthropogenic & Distance from nearest roads, paths \& trails $(\mathrm{km})$ \\
\hline Distance to villages & Macro & Anthropogenic & Distance from nearest villages $(\mathrm{km})$ \\
\hline Distance to water & Macro & Environmental & $\begin{array}{l}\text { Distance from major streams \& rivers as calculated from a digital elevation } \\
\text { model-derived hydrology layer }(\mathrm{km})\end{array}$ \\
\hline Elevation & Micro & Environmental & Elevation recorded by global positioning system at the camera-trap station (m) \\
\hline Forest score & Macro & Environmental & $\begin{array}{l}\text { Measure of habitat quality derived from high-resolution satellite imagery within } \\
50 \mathrm{~m} \text { of the camera-trap station }\end{array}$ \\
\hline Human activities & Micro & Anthropogenic & $\begin{array}{l}\text { No. of types of human activities within } 20 \times 20 \mathrm{~m} \text { plot around the camera-trap } \\
\text { station }\end{array}$ \\
\hline $\begin{array}{l}\text { Mammals \& galli- } \\
\text { forms }>500 \mathrm{~g}\end{array}$ & Micro & Anthropogenic & Mean no. of detections per station per day for mammals \& galliformes $>500 \mathrm{~g}$ \\
\hline $\begin{array}{l}\text { Mammals \& galli- } \\
\text { forms }<500 \mathrm{~g}\end{array}$ & Micro & Anthropogenic & Mean no. of detections per station per day for mammals \& galliformes $<500 \mathrm{~g}$ \\
\hline Protection status & Macro & Anthropogenic & Current level of anti-poaching patrol activity for an area ( 0 or 1$)$ \\
\hline Terrain ruggedness & Macro & Anthropogenic & $\begin{array}{l}\text { Topographic position index within } 270 \mathrm{~m} \text { radius around the camera-trap station; } \\
\text { derived from SRTM } 30 \mathrm{~m} \text { digital elevation model }\end{array}$ \\
\hline Vegetation density & Micro & Environmental & $\begin{array}{l}\text { Mean proportion of vegetation sheet visible at four locations around the } \\
\text { camera-trap station }\end{array}$ \\
\hline Water microhabitat & Micro & Environmental & $\begin{array}{l}\text { No. of water sources (streams, ponds) within } 20 \times 20 \mathrm{~m} \text { plot around the } \\
\text { camera-trap station }\end{array}$ \\
\hline
\end{tabular}

${ }^{1}$ Micro-scale covariates were assessed in situ around each camera-trap location; macro-scale covariates were calculated in $R$ using satellite imagery, digital elevation models, and available GIS datasets.

${ }^{2}$ Anthropogenic covariates are features that may influence hunting pressure directly or indirectly; environmental covariates are features related to habitat quality.

trapping period to meet the assumption of closure; spatial independence was confirmed during data analysis (see below). We pooled camera-trap data into 15 -day occasions, resulting in at least four sampling occasions for all stations. To determine effort at each station we combined total camera-trap nights for each camera. Detection-nondetection matrices were produced for all stations, with data from the two camera traps at each station combined and analysed as a single station. Single-covariate models were run in the unmarked package (Fiske \& Chandler, 2011). We first constructed a null model that did not include any covariates and then ran single-covariate models. Because little is known about the species, we were unable to develop a priori hypotheses regarding which factors could influence species occupancy. Therefore, we decided to test each covariate individually to first assess its importance in explaining species occupancy, and only later combine significant covariates into combination models. We included camera-trapping effort as a covariate on detection probability $(\mathrm{P})$. Akaike's information criterion (AIC) was used to rank candidate models (Burnham \& Anderson, 2003). We considered any model within two $\triangle$ AIC units of the top model to be significant. We evaluated the strength of each covariate using $\mathrm{P}$ values.
To estimate local abundance of the Annamite striped rabbit at our fine-grid locations we identified individual rabbits based on their unique striping patterns (Supplementary Plate 1). We were thus able to avoid double-counting within a sampling occasion. We pooled camera-trap data into 15-day occasions, then determined the number of individuals detected for each occasion. We used N-mixture models, which estimate site-level abundance using spatially and temporally replicated counts (Royle, 2004), to estimate the number of individual rabbits at each camera-trap station. Because no individual rabbit was photographed at two stations, we consider our stations for the fine-grid survey to be spatially independent. As with the occupancy model, we consider our trapping period to approximate temporal population closure. N-mixture models cannot account for heterogeneity in detection among individuals, and therefore resulting abundance estimates may not accurately reflect true abundance (Barker et al., 2018). Nonetheless, the estimates we provide present a meaningful baseline against which to assess future population change (see Discussion). N-mixture analyses were run in unmarked (Fiske \& Chandler, 2011). Models were run with an underlying Poisson distribution. Although the zero-inflated Poisson and negative binomial may be used when count 
data are overdispersed, we did not find this to be the case with our dataset.

\section{Results}

We obtained data from 138 coarse-grid stations $(20,776$ camera-trap nights in total) and 128 fine-grid stations $(8,404$ camera-trap nights in total). We obtained 100 independent detections across 22 stations from the coarse grid, and 54 independent detections across 14 stations from the fine grid. All fine-grid detections occurred in the Saola Nature Reserves, with no photographs from Bach Ma National Park. We identified a total of 27 individuals from the fine-grid data. From 17,190 camera-trap nights in the non-systematic survey in the Hue Saola Nature Reserve we obtained an additional 142 independent detections across 12 stations (Table 1).

The Annamite striped rabbit was primarily solitary. Only two of $296(<1 \%)$ independent detections showed two individuals in the same photographic sequence. For one of these records, a third individual followed the first two individuals 22 minutes later. All records occurred during 18.00-04.00, with a peak in activity during 01.00-03.00. (Fig. 2), indicating that the species is nocturnal. We recorded the species at elevations of 198-1,304 m (mean $=637 \pm$ SD 290; Fig. 3).

Naive occupancy for the Annamite striped rabbit was 0.13 across all sites, and predicted occupancy probability $(\psi)$ for the top-ranked model was $0.18 \pm$ SD 0.04 . The probability of detection was $0.36 \pm$ SD 0.05 . The top model contained only one covariate, detection rate of mammals and galliforms $>500 \mathrm{~g}$ (Table 3; Supplementary Fig. 3). All other models had a $\Delta$ AIC $>_{7}$ from the top-ranked model. Annamite striped rabbit occupancy was strongly and positively correlated with the number of detections of other hunting-sensitive species (Fig. 4), and all other predictors, including habitat-based covariates, were uninformative in explaining occurrence (Fig. 5).

The N-mixture model estimated a mean local abundance $(\lambda)$ of $0.57 \pm$ SE 0.20 individuals per station in the Saola Nature Reserves. Detection probability $(\mathrm{P})$ was estimated to be $0.19 \pm \mathrm{SE}$ 0.07. With no detections in the Bach Ma National Park fine-grid site, we could not estimate local abundance with $\mathrm{N}$-mixture models. As survey effort in this site was high, we interpret this result as indicating that true local abundance at this site is zero or close to zero.

\section{Discussion}

As with many other lagomorphs, the Annamite striped rabbit is nocturnal. Nocturnal activity is often explained by predator avoidance, as many natural predators hunt primarily by sight. The species' solitary behaviour is also consistent with most leporids (Cowan \& Bell, 1986). The two observed

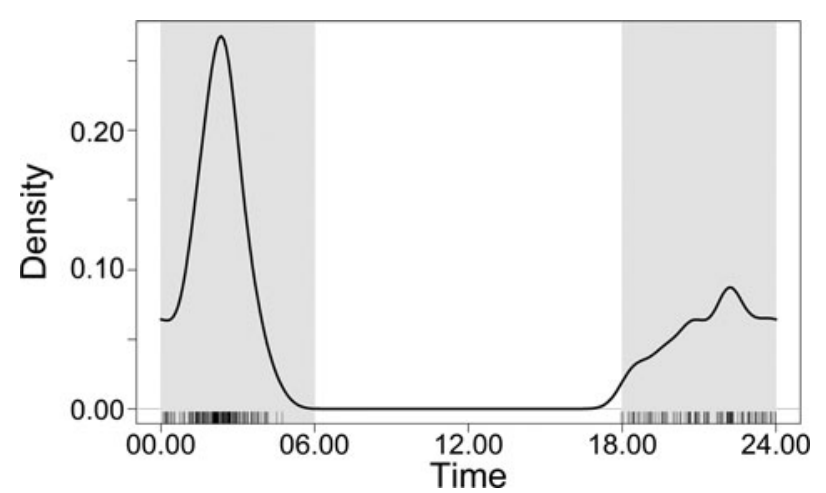

FIG. 2. Kernel density estimate of daily activity patterns for the Annamite striped rabbit Nesolagus timminsi based on

camera-trap data. The vertical lines on the $\mathrm{x}$-axis indicate times of individual independent detections $(\Delta=60, \mathrm{n}=296)$, and the grey shading represents night-time.

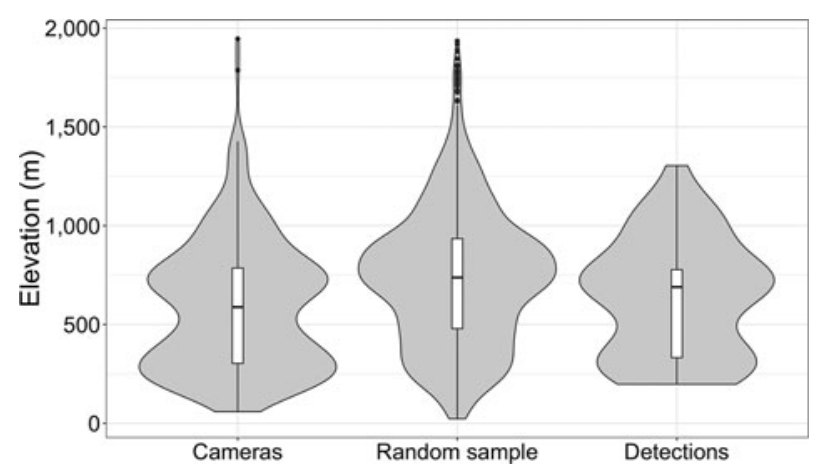

FIG. 3. Distribution of all camera traps, random sample points $(n=2,000)$ across the study areas, and detections of the Annamite striped rabbit, by elevation.

Annamite striped rabbit pairs may indicate behaviour related to breeding. In both sequences, the first rabbit moves through the frame, followed immediately by a second rabbit on a direct path to the first. All individuals were approximately the same size and are unlikely to be parent and offspring. However, because we have so few records of paired individuals and were unable to determine sex from the photographs, it is not possible to draw conclusions related to reproduction behaviour from our data.

Our analysis indicates that the species shows no strong elevational preferences (Fig. 3), which is consistent with the limited information available. Dang et al. (2001) reported an individual found in a snare at $200 \mathrm{~m}$ elevation but also noted that hunters report the species at higher elevations. Although Abramov et al. (2008) suggested that the species can probably utilize areas as low as sea level, we did not record the species at extremely low elevations, possibly because lowland areas are readily accessible and have higher levels of past hunting pressure. The fact that we did not record the species above 1,304 $\mathrm{m}$ could indicate that the species does not occur in forest with montane characteristics, 
TABle 3. Occupancy model results for the Annamite striped rabbit, ranked by $\Delta$ AIC. Bold font indicates significance at $\mathrm{P}<0.05$.

\begin{tabular}{|c|c|c|c|c|c|c|}
\hline Covariate & $\Delta \mathrm{AIC}$ & Coefficient & SE & $\mathrm{Z}$ & AIC & $\mathrm{P}$ \\
\hline Mammals \& galliforms $>500 \mathrm{~g}$ & 0.0000 & 0.6411 & 0.2528 & 2.5356 & 275.9922 & 0.0112 \\
\hline Forest score & 7.0786 & -0.2159 & 0.2070 & -1.0432 & 283.0706 & 0.2969 \\
\hline Mammals \& galliforms $<500 \mathrm{~g}$ & 7.3847 & 0.0025 & 0.2371 & 0.0105 & 283.3769 & 0.9916 \\
\hline Bamboo & 9.8017 & -1.0710 & 0.7412 & -1.4449 & 285.7937 & 0.1485 \\
\hline Protection status & 11.4273 & 0.8513 & 0.5112 & 1.6653 & 287.4193 & 0.0959 \\
\hline Elevation & 13.0812 & 0.2682 & 0.2511 & 1.0684 & 289.0732 & 0.2853 \\
\hline Terrain ruggedness & 13.4843 & -0.2061 & 0.2451 & -0.8408 & 289.4763 & 0.4004 \\
\hline Distance to roads & 14.0107 & -0.1125 & 0.2069 & -0.4328 & 290.0027 & 0.6652 \\
\hline Dead fallen trees & 14.0591 & 0.0860 & 0.2294 & 0.3749 & 290.0511 & 0.7078 \\
\hline Distance to village & 14.0866 & -0.0841 & 0.2538 & -0.3314 & 290.0786 & 0.7403 \\
\hline Water microhabitat & 14.1593 & -0.0486 & 0.2556 & -0.1902 & 290.1513 & 0.8491 \\
\hline Canopy closure & 14.1744 & -0.0366 & 0.2461 & -0.1485 & 290.1664 & 0.8819 \\
\hline Vegetation density & 14.1906 & 0.0185 & 0.2444 & 0.0756 & 290.1826 & 0.9398 \\
\hline Distance to water & 14.1914 & 0.0170 & 0.2404 & 0.0706 & 290.1834 & 0.9437 \\
\hline Human activities & 14.1951 & -0.0086 & 0.2438 & -0.0353 & 290.1871 & 0.9718 \\
\hline
\end{tabular}

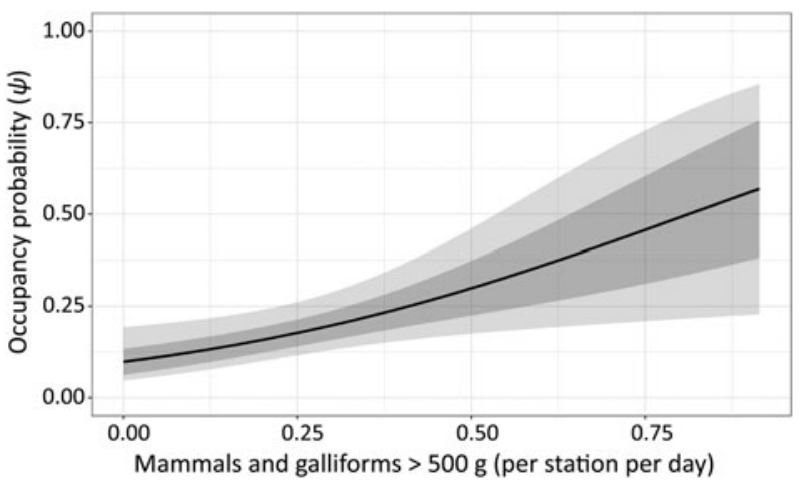

FIG. 4. Response curve showing change in modelled occupancy $(\psi)$ with detection rates for mammals and galliforms $>500 \mathrm{~g}$.

although our survey effort at high elevations was limited and therefore additional work is needed to investigate this.

Numerous studies have demonstrated that species occurrence is driven by multiple factors operating at various spatial scales (Gerber et al., 2012; Koerner et al., 2017). We hypothesized that occurrence of the Annamite striped rabbit would be influenced by a combination of current habitat and anthropogenic factors. Our results show that detections of other snaring-sensitive species, which we interpret as an indication of past hunting pressure, is the best predictor of occurrence of the Annamite striped rabbit in our study sites. The failure of other predictors to explain occupancy was unexpected. We believe that this finding is explained by the fact that past hunting pressure has overwhelmed environmental relationships. In this scenario, the Annamite striped rabbit would, in the absence of excessive hunting pressure, be more widely distributed and abundant in the landscape. As a result of the overwhelming snaring pressure in the Annamites (Gray et al., 2017, 2018), several endemic mammal species, including the saola, have distributions determined almost exclusively by hunting pressure (Timmins et al., 2016b). We postulate that the Annamite striped rabbit follows a similar distribution pattern within our study site. Given the range of environmental covariates we measured, and the fact that occupancy is strongly correlated to presence of other hunting-sensitive species, we suggest that the Annamite striped rabbit exhibits characteristics of a refugee species whose distribution is driven by anthropogenic pressures rather than habitat preferences (Kerley et al., 2012). Further studies are needed to investigate whether the Annamite striped rabbit also utilizes suboptimal but safer habitats, a pattern that has been observed for other refugee species (Bocherens et al., 2015).

Local abundance patterns from our fine-grid data indicate that the Annamite striped rabbit is extirpated locally in the central part of Bach Ma National Park, and present at low to moderate densities in the Saola Nature Reserves. This finding is generally consistent with our coarse-grid data, which indicated the species was present but rare across the National Park, but not uncommon in the Saola Nature Reserves. Although intensive defaunation has occurred across all parts of this landscape, Bach Ma National Park appears to be emptier than the neighbouring Saola Nature Reserves, based on detections of other hunting-sensitive species (Table 1). In addition, the Saola Nature Reserves have some level of active anti-poaching protection, whereas enforcement efforts in Bach Ma are extremely low. We suggest that more intensive snaring in Bach $\mathrm{Ma}$, exacerbated by the lack of enforcement efforts, has led to the probable extirpation of the species from large parts of the protected area. The difference in local abundances between two areas with similar habitat offers additional evidence for occurrence patterns driven by hunting.

As this is the first study to estimate local abundance $(\lambda)$ for the species, we cannot compare our estimates for the Saola Nature Reserves to past studies. However, because the Saola Nature Reserves have experienced heavy hunting 

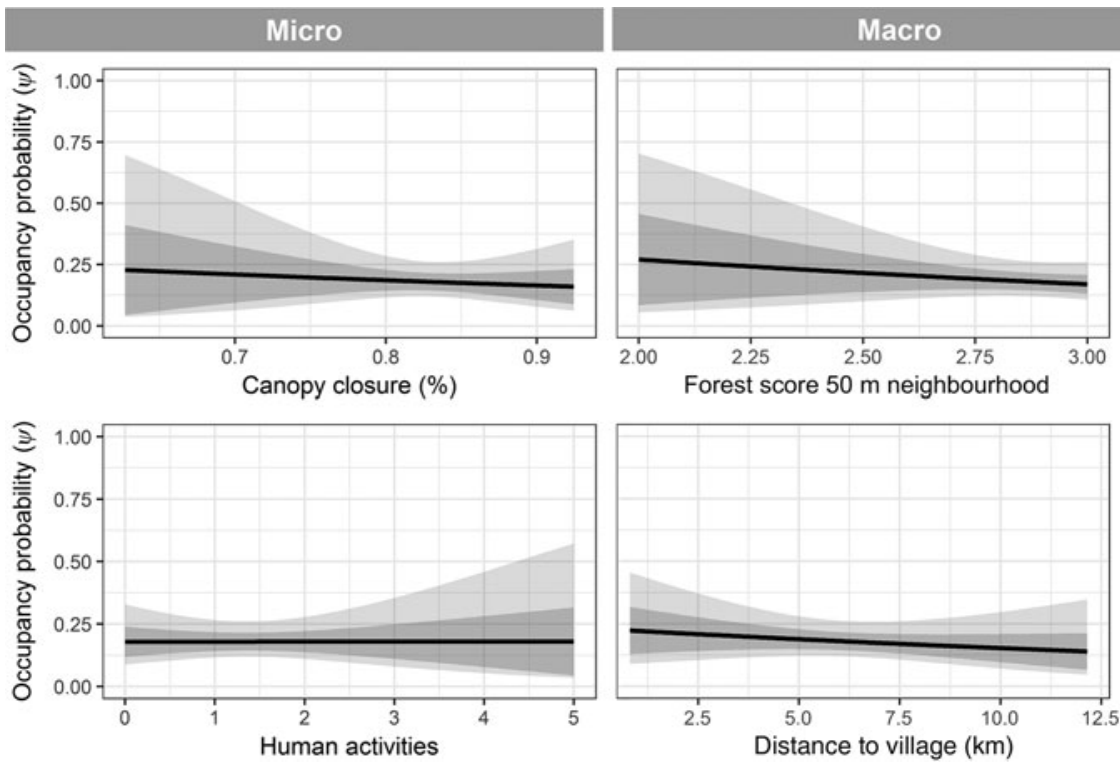

FIG. 5. Annamite striped rabbit occupancy response curves, showing example non-significant results for each representative covariate class. pressure, we believe that the local abundance is well below what would exist under undisturbed conditions. Although no area in the Annamites landscape is unaffected by snaring, there are sites within the species' range that, on the basis of expert assessments and limited camera trapping, have not been as heavily affected as our study sites. We recommend additional camera trapping at these sites, to obtain comparable local abundance estimates for the Annamite striped rabbit. It is likely that only surveys in less hunted areas, where the impact of hunting on distribution is weaker, will be able to offer insight into the ecology of the species.

Our results provide information that is directly applicable to Annamite striped rabbit conservation. The camera trapping provides spatially explicit data that can be used for targeted anti-poaching work. With the complete or functional extinction of numerous flagship mammal species from the Annamites, including regionally important species such as the Javan rhinoceros Rhinocerous sondaicus (Brook et al., 2012) and tiger Panthera tigris (Walston et al., 2010), and endemics such as the saola (Tilker et al., 2017), the Annamite striped rabbit may be the highest priority terrestrial mammal species with sizeable populations remaining at our study sites. We therefore recommend that current antipoaching patrols concentrate snare-removal efforts in locations where the species was recorded. Our data further support an ongoing initiative by conservation stakeholders to gazette the Palé area as a protected area. The occurrence of the Annamite striped rabbit in multiple locations within this area, along with other conservation-priority species such as Owston's civet and the Asiatic black bear Ursus thibetanus (Tilker, Nguyen \& Wilting, unpubl. data), underscores the importance of this area for conservation.

Ultimately, conservation stakeholders need to embed species conservation programmes into a holistic, adaptive management framework (Keith et al., 2011). Assessing population trends over time is a key component of adaptive management and requires a baseline for assessment of future changes. Here we establish two baselines for the Annamite striped rabbit: at the landscape scale and at a local scale within the Saola Nature Reserves. For long-term adaptive management of the species in this landscape we recommend repeating the systematic camera trapping in the near future to assess possible changes in the population within these areas in response to continued snare-removal efforts.

Several Annamite endemic species are facing imminent extinction as a result of intensive snaring. The saola is so rare that conservation breeding is now believed to be the last hope to save the species (Tilker et al., 2017). The large-antlered muntjac and Edwards's pheasant are both Critically Endangered (BirdLife International, 2016; Timmins et al., 2016a), and the latter may already be extinct in the wild (Grainger et al., 2017). The status of the Annamite striped rabbit is not as severe but the lack of records from Bach Ma National Park is cause for concern. The status and population trend of the Annamite striped rabbit in this protected area, although better than for other endemic species that have probably become extirpated there in recent years (including the saola and large-antlered muntjac), appears to be following the trajectory of these hunting-sensitive species (R. Timmins, pers. comm., 2018). Without immediate and effective anti-poaching efforts, the Annamite striped rabbit may become as rare as the saola.

Acknowledgements We thank the staff of the WWF-CarBi project for providing extensive logistical support; Bach Ma National Park, the Thua Thien Hue and Quang Nam Saola Nature Reserves, and Xe Sap National Protected Area for providing permissions and personnel to conduct this research; and our field team leaders in Viet Nam and Lao. Funding for the surveys was provided by the German Federal Ministry of Education and Research (BMBF FKZ: 01LN1301A), 
Leibniz-IZW, Point Defiance Zoo and Aquarium, Safari Club International, and Critical Ecosystem Partnership Fund. AT received support through a Fulbright scholarship. The CarBi project was provided by Internationale Klimaschutzinitiative of the Federal Ministry for the Environment, Nature Conservation, and Nuclear Safety (BMBU) and Kreditanstalt für Wiederaufbau (KfW). AT would like to thank Rob Timmins for discussions about the Annamite striped rabbit, and Barney Long, Tom Gray, and Wes Sechrest for support while working in the Annamites. We thank two anonymous reviewers whose input substantially improved this article.

Author contributions Design of systematic camera-trap survey: AT, RS, AW; fieldwork for systematic camera-trap survey: AT, AN; design of non-systematic survey: ML; fieldwork for non-systematic survey: TVN, ATN; analysis of survey data: AT, JFA; analysis of remotesensing data: $\mathrm{TB}, \mathrm{JN}$; writing: AT, JFA, AW; revision of article: all authors.

\section{Conflicts of interest None.}

Ethical standards This research complies with the Oryx Code of Conduct.

\section{References}

Abramov, A., Timmins, R.J., Touk, D., Duckworth, J.W. \& Steinmetz, R. (2008) Nesolagus timminsi. In The IUCN Red List of Threatened Species 2008: e.T41209A10412274. Http://dx.doi.org/10. 2305/IUCN.UK.2008.RLTS.T41209A10412274.en [accessed 3 August 2018].

Averianov, A.O., Abramov, A.V. \& Tikhonov, A.N. (2000) A New Species of Nesolagus (Lagomorpha, Leporidae) from Vietnam with Osteological Description. Zoological Institute, St. Petersburg, Russia.

B ALTZER, M.C. (2001) Towards a Vision for Biodiversity Conservation in the Forests of the Lower Mekong Ecoregion Complex: Summary of the Biological Assessment for the Ecoregion Biodiversity Conservation Program in the Forests of the Lower Mekong Ecoregion Complex. WWF Indochina, Hanoi, Viet Nam.

Barker, R.J., Schofield, M.R., Link, W.A. \& Sauer, J.R. (2018) On the reliability of $\mathrm{N}$-mixture models for count data. Biometrics, 74 , 369-377.

Birdife International (2016) Lophura edwardsi. In The IUCN Red List of Threatened Species 2016: e.T45354985A95145107. Http://dx. doi.org/10.2305/IUCN.UK.2016-3.RLTS.T45354985A95145107.en [accessed 3 August 2018]

Bocherens, H., Hofman-Kamińska, E., Drucker, D.G., Schmölcke, U. \& KowalczyK, R. (2015) European bison as a refugee species? Evidence from isotopic data on Early Holocene bison and other large herbivores in northern Europe. PLoS ONE, 10, eo11509o.

Brook, S.M., de Groot, P.V., Scott, C., Boag, P., Long, B., Ley, R. E. et al. (2012) Integrated and novel survey methods for rhinoceros populations confirm the extinction of Rhinoceros sondaicus annamiticus from Vietnam. Biological Conservation, 155, 59-67.

Burnham, K.P. \& Anderson, D.R. (2003) Model Selection and Multimodel Inference: A Practical Information-Theoretic Approach. Springer Verlag, New York, USA.

Cardillo, M., Mace, G.M., Gittleman, J.L., Jones, K.E., Bielby, J. \& Purvis, A. (2008) The predictability of extinction: biological and external correlates of decline in mammals. Proceedings of the Royal Society of London B: Biological Sciences, 275, 1441-1448.
Cowan, D.P. \& BelL, D.J. (1986) Leporid social behaviour and social organization. Mammal Review, 16, 169-179.

Dang, C.N., Abramov, A.V., Tikhonov, A.N. \& Averianov, A.O. (2001) Annamite striped rabbit Nesolagus timminsi in Vietnam. Acta Theriologica, 46, 437-440.

Duckworth, J.W., Batters, G., Belant, J.L., Bennett, E.L., Brunner, J., Burton, J. et al. (2012) Why South-east Asia should be the world's priority for averting imminent species extinctions, and a call to join a developing cross-institutional programme to tackle this urgent issue. Sapiens, 5, 77-95.

Fiske, I. \& Chandler, R. (2011) unmarked: an $R$ package for fitting hierarchical models of wildlife occurrence and abundance. Journal of Statistical Software, 43, 1-23.

Gerber, B.D., Karpanty, S.M. \& Randrianantenaina, J. (2012) The impact of forest logging and fragmentation on carnivore species composition, density and occupancy in Madagascar's rainforests. Oryx, 46, 414-422.

Grainger, M.J., Ngoprasert, D., McGowan, P.J. \& Savini, T. (2017) Informing decisions on an extremely data poor species facing imminent extinction. Oryx, published online 18 August 2017.

Gray, T.N., Lynam, A.J., Seng, T., Laurance, W.F., Long, B., Scotson, L. \& Ripple, W.J. (2017) Wildlife-snaring crisis in Asian forests. Science, 355, 255-256.

Gray, T.N., Hughes, A.C., Laurance, W.F., Long, B., Lynam, A.J., O'Kelly, H. et al. (2018) The wildlife snaring crisis: an insidious and pervasive threat to biodiversity in Southeast Asia. Biodiversity and Conservation, 27, 1031-1037.

Harrison, R.D., Sreekar, R., Brodie, J.F., Brook, S., Luskin, M., O'Kelly, H. et al. (2016) Impacts of hunting on tropical forests in Southeast Asia. Conservation Biology, 30, 972-981.

Keith, D.A., Martin, T.G., McDonald-Madden, E. \& Walters, C. (2011) Uncertainty and adaptive management for biodiversity conservation. Biological Conservation, 144, 1175-1178.

Kerley, G.I.H., Kowalczy , R. \& Cromsigt, J.P.G.M. (2012) Conservation implications of the refugee species concept and the European bison: king of the forest or refugee in a marginal habitat? Ecography, 35, 519-529.

Koerner, S.E., Poulsen, J.R., Blanchard, E.J., Okouyi, J. \& CLARK, C.J. (2017) Vertebrate community composition and diversity declines along a defaunation gradient radiating from rural villages in Gabon. Journal of Applied Ecology, 54, 805-814.

Niedballa, J., Sollmann, R., Bin Mohamed, A., Bender, J. \& Wilting, A. (2015) Defining habitat covariates in camera-trap based occupancy studies. Scientific Reports, 5, 17041.

Niedballa, J., Sollmann, R., Courtiol, A. \& Wilting, A. (2016) camtrapR: an $R$ package for efficient camera trap data management. Methods in Ecology and Evolution, 7, 1457-1462.

QGIS Development Team (2016) QGIS. A Free and Open Source Geographic Information System. Https://qgis.org/ [accessed 22 October 2018].

R Development Core Team (2016) R: A Language and Environment for Statistical Computing. R Foundation for Statistical Computing, Vienna, Austria. Http://www.R-project.org/ [accessed 22 October 2018].

Redford, K.H. (1992) The empty forest. BioScience, 42, 412-422.

Royle, J.A. (2004) N-mixture models for estimating population size from spatially replicated counts. Biometrics, 6o, 108-115.

Schipper, J., Chanson, J.S., Chiozza, F., Cox, N.A., Hoffmann, M., Katariya, V. et al. (2008) The status of the world's land and marine mammals: diversity, threat, and knowledge. Science, 322, 225-230. 
Sodhi, N.S., Koн, L.P., Brook, B.W. \& NG, P.K. (2004) Southeast Asian biodiversity: an impending disaster. Trends in Ecology \& Evolution, 19, 654-660.

Sollmann, R., Mohamed, A., Samejima, H. \& Wilting, A. (2013) Risky business or simple solution - relative abundance indices from camera-trapping. Biological Conservation, 159, 405-412.

Stellman, J. M., Stellman, S. D., Christian, R., Weber, T., \& Tomasallo, C. (2003) The extent and patterns of usage of Agent Orange and other herbicides in Vietnam. Nature, 422, 681-687.

Sterling, E.J. \& Hurley, M.M. (2005) Conserving biodiversity in Vietnam: applying biogeography to conservation research. Proceedings of the California Academy of Sciences, 56, 98-114.

Surridge, A.K., Timmins, R.G., Hewitt, G.M. \& Bell, D.J. (1999) Striped rabbits in Southeast Asia. Nature, 400, 726.

Tilker, A. (2014) A Survey of Eastern Areas of Xe Sap National Protected Area, Lao PDR, for Saola and Other Large Ungulates; Final Report to Global Wildlife Conservation and the Saola Working Group. WWF Greater Mekong Program, Vientiane, Lao PDR.

Tilker, A., Long, B., Gray, T.N., Robichaud, W., Van, T.N., NGUyen, L.V. et al. (2017) Saving the saola from extinction. Science, 357, 1248-1248.
Timmins, R.J., Duckworth, J.W., Robichaud, W., Long, B., Gray, T.N.E. \& Tilker, A. (2016a) Muntiacus vuquangensis. In The IUCN Red List of Threatened Species 2016: e.T44703A22153828. Http://dx. doi.org/10.2305/IUCN.UK.2016-2.RLTS.T44703A22153828.en [accessed 3 August 2018].

Timmins, R.J., Hedges, S. \& Robichaud, W. (2016b) Pseudoryx nghetinhensis. In The IUCN Red List of Threatened Species 2016: $e$. T18597A46364962. Http://dx.doi.org/10.2305/IUCN.UK.2016-2. RLTS.T18597A46364962.en [accessed 3 August 2018].

Tordoff, A., Timmins, R., Smith, R. \& Mai, K.V. (2003) A Biological Assessment of the Central Truong Son Landscape. Central Truong Son Initiative Report No. 1. WWF Indochina, Hanoi, Viet Nam.

Walston, J., Robinson, J.G., Bennett, E.L., Breitenmoser, U., DA Fonseca, G.A., Goodrich, J. et al. (2010) Bringing the tiger back from the brink-the six percent solution. PLoS Biology, 8(9), e1000485.

Yen, P., Ziegler, S., Huettmann, F. \& Onyeahialam, A.I. (2005) Change detection of forest and habitat resources from 1973 to 2001 in Bach Ma National Park, Vietnam, using remote sensing imagery. International Forestry Review, 7, 1-8. 